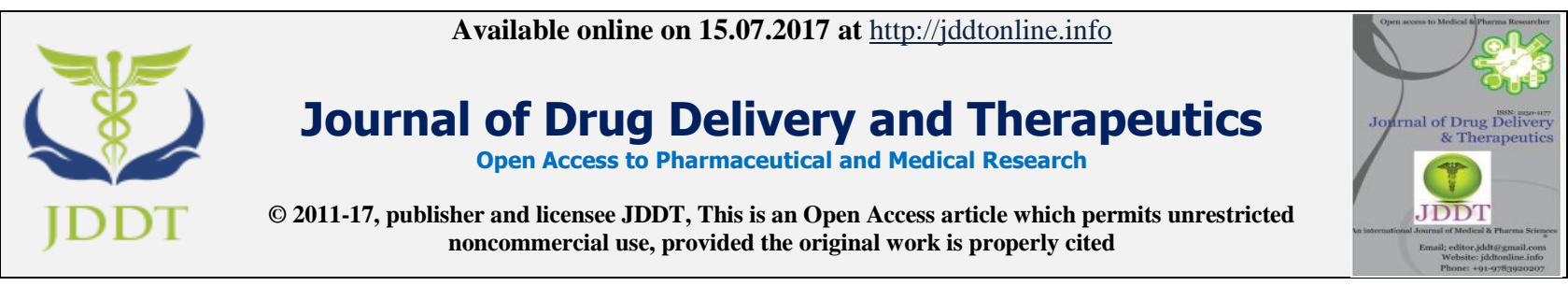

Open $\odot$ Access

Research Article

\title{
DEVELOPMENT OF STEVIOSIDE LOADED PELLETS FOR REGULATING THE BLOOD GLUCOSE LEVEL IN DIABETES: IN VIVO- IN VITRO CHARACTERIZATION
}

\author{
Pankaj V. Dangre*, Vijay D. Fating, Seema B. Wakodkar, Mangesh D. Godbole \\ Department of Pharmaceutics, Kamla Nehru College of Pharmacy, Butibori, Nagpur-441108, Maharashtra, India
}

\begin{abstract}
Stevioside is a non-caloric sweetener and used as the alternative to sugar in many countries. It has been reported to have promising antidiabetic activity. In the present investigation, we have developed a multi-particulate system of stevioside consisting of nonpareil pellets for antidiabetic patients. The drug loading on pellets was performed by solvent evaporation and suspension layering method. The loaded pellets were evaluated for yield (\%), drug loading efficiency (\%), flow properties and in-vitro dissolution study. The stevioside loaded pellets (STL 4) showed yields (92.36\%), drug loading efficiency $(86.60 \%)$, friability $(0.74 \%)$, drug release $(98.31 \%)$ within $60 \mathrm{~min}$ and good flow properties. The in vivo study indicates the significant reduction in blood glucose levels in alloxan induced diabetic rats after administration of stevioside loaded formulation (STL 4). The developed formulation of stevioside pellets can find its dual applications as a sugar substitute having the potential anti-hyperglycemic effect which can be given easily and safely to the diabetic patients.
\end{abstract}

Keywords: Stevioside; pellets; non-caloric sweetener; anti-hyperglycemic; diabetes.

Article Info: Received 08 May, 2017; Review Completed 30 June, 2017; Accepted 01 July, 2017; Available online 15 July, 2017

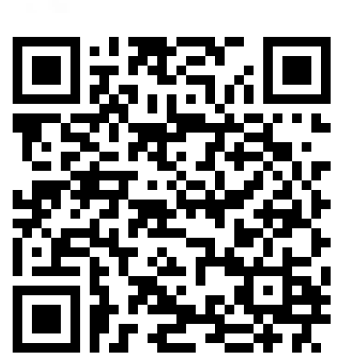

Cite this article as:

Dangre PV, Fating VD, Wakodkar SB, Godbole MD, Development of stevioside loaded pellets for regulating the blood glucose level in diabetes: in vivo- in vitro characterization, Journal of Drug Delivery and Therapeutics. 2017; 7(4):59-65

DOI: http://dx.doi.org/10.22270/jddt.v7i4.1461

*Address for Correspondence

Pankaj V. Dangre, Department of Pharmaceutics, Kamla Nehru College of Pharmacy, Butibori, Nagpur, Maharashtra, India.

Email: pankaj_dangre@rediffmail.com

\section{INTRODUCTION}

Diabetes Mellitus is a chronic metabolic disorder which at present has affected more than 400 million people across the globe. It is the $7^{\text {th }}$ root cause of death universally and is progressing with a constant pace ${ }^{1}$. Recent statistics and surveys have forecast to affect 592 million people with diabetes by 2030 globally ${ }^{2}$. Likewise, in India, it is threatened seriously with the highest number (32 million in 2000) of the diabetic population followed by China and USA $^{3}$. Moreover, it has been proposed that from 2006 to 2025 the diabetic population will grow rapidly from 40 million to 69.9 million $^{4}$. The hyperglycemic state of a diabetic patient is difficult to treat but the blood glucose level can be managed by administration of a daily dose of the antidiabetic drug 5 . Antidiabetic drug from natural sources is preferred because of their less toxicity and a negligible side effect on to the body ${ }^{6}$.

Stevioside is a sweet tasting glycoside present in large quantity in the leaves of Stevia rebaudiana Bertoni (Asteraceae) ${ }^{7}$. It is composed of stevia, a diterpenic carboxylic alcohol with three glucose molecules attached to an aglycone, the steviol moiety ${ }^{8}$. It is about 200-300 times sweeter than sugar; its sweetness potency is alike to that of aspartame ${ }^{9}$. Stevia is finding its worldwide application as a non-caloric sweetener ${ }^{10}$. Apart from its sweetness properties, the stevioside has promising contraceptive ${ }^{11}$, antihypertensive ${ }^{12}$ and antidiabetic potential ${ }^{13-15}$. Stevioside has been used for 
many years in the treatment of diabetes in several countries $^{16,17}$. The antidiabetic potential of stevioside is due to the stimulation of insulin secretion from the beta cells of the pancreas ${ }^{18}$.

The present investigation aimed to develop a multiparticulate system consisting of stevioside loaded pellets. Multi-particulate system have many advantages over the single unit dosage form like, better distribution in gastrointestinal tract, less dependent on gastric emptying, avoidance of local irritation, less inter and intra-subject variability ${ }^{19}$ and therefore considered for present investigation. Stevioside being a non-calorie sweetener can be given as a substitute for sugar to the diabetic patient. Besides, a sweetener stevioside through its anti-hyperglycemic action helps to regulate the blood glucose level. Therefore, the loaded pellets were evaluated for its antidiabetic potential.

\section{MATERIAL AND METHODS}

Stevioside powder was procured from Yucca Enterprises, Mumbai, India. Glibenclamide was a kind gift sample received from Alkem Laboratories, Mumbai, India. The non-pareil pellets were obtained from Zim Laboratories, Nagpur. HPMC-K4M was provided by the Colorcon Asia Pvt. Ltd., Mumbai, India. Polyvinyl pyrrolidone (PVP) K30 was purchased from Himedia Ltd., India. The alcohol and the other chemical used were purchased from Loba Chemie, Mumbai, India.

\subsection{Method of loading of stevioside pellets}

The loading on pellet was carried out by two methods i.e., 1) Solvent evaporation and 2) Suspension layering method.

\subsubsection{Solvent evaporation method}

In this method, the stevioside powder in different weight ratios (1 to $4 \% \mathrm{w} / \mathrm{v}$ ) (Table 1 ) was dissolved in ethanol $(50 \mathrm{~mL})$. The mixture was sonicated for $15 \mathrm{~min}$ to ensure complete solubilization of the compound. The suitable quantity of pellets $(100 \mathrm{mg} / 10 \mathrm{~mL})$ was incorporated into the mixture. The mixture was then kept at $80^{\circ} \mathrm{C}$ in hot air oven for about $45 \mathrm{~min}$. After a specific time interval, the loaded pellets were collected and stored properly at ambient temperature until further use.

Table 1: Method of formulation stevioside loaded pellets

\begin{tabular}{|c|c|c|}
\hline \multirow{2}{*}{ Bath code } & Solvent evaporation method & Suspension layering method \\
\cline { 2 - 3 } & Stevioside (\% w/v) in ethanol & Stevioside (\% w/v) in coating solution \\
\hline STE1 & $1 \%$ & - \\
\hline STE2 & $2 \%$ & - \\
\hline STE3 & $3 \%$ & - \\
\hline STE4 & $4 \%$ & $1 \%$ \\
\hline STL1 & - & $2 \%$ \\
\hline STL2 & - & $3 \%$ \\
\hline STL3 & - & $4 \%$ \\
\hline
\end{tabular}

\subsubsection{Suspension layering method}

This method involves wetting of the core material with a coating solution containing the drug. The process was continued with intermittent drying till the drug was completely loaded onto the core. Stevioside powder in different weight ratios (1 to $4 \% \mathrm{w} / \mathrm{v})$ was homogeneously dispersed in coating solution (Table 1). The coating solution composed of carrier HPMC-K4M $(2 \% \mathrm{w} / \mathrm{w})$ and binder PVP-K30 (15\% w/w) dissolved in ethanol. Basic core non-pareil pellets (18\#20) were transferred into coating pan ( $\mathrm{R} \& \mathrm{D}$ coater) and the prepared coating solution was sprayed on it. The spray rate and inlet air temperature were adjusted in such a way that the drug coated pellets reached a temperature of about $37^{\circ} \mathrm{C}-42^{\circ} \mathrm{C}$. The process parameters of a coating are given in Table 2 . The talc was frequently added to the coating pan in order to avoid over wetting of the drug coated pellets as it may cause agglomeration. The dried pellets were sized on a sifter to remove agglomerates, broken pellets, and fine powder. The weight of the pellets was checked and the yield was noted.

\subsection{Evaluation of drug loaded pellets}

\subsubsection{Percentage yield}

The yield of the pellets was determined as a percentage of the ratio of the initial weight of the pellets before the loading process to the final weight gain after loading. The percentage yield was calculated according to the following formula.

Percentage yield $(\% \mathrm{w} / \mathrm{w})=$

Weight of pellets before loading/Total weight after loading of the drug $\times 100$ 
Table 2: The process parameters for stevioside loaded pellets

\begin{tabular}{|l|l|l|}
\hline Sr. No. & Process Parameter & \multicolumn{1}{|c|}{ Specification } \\
\hline 1. & Pan size & 4 inch \\
\hline 2. & Batch size & $10 \mathrm{~g}$ \\
\hline 3. & Spray rate & $0.5-2 \mathrm{~g} / \mathrm{min}$ \\
\hline 4. & Air flow & $0.3-1.5 \mathrm{bar}$ \\
\hline 5. & Atomizing air pressure & $2 \mathrm{~b} / \mathrm{in}^{2}$ \\
\hline 6. & Nozzle diameter & $0.8 \mathrm{~mm}$ \\
\hline 7. & Inlet air temperature & $60-70^{\circ} \mathrm{C}$ \\
\hline 8. & Product temperature & $40-50^{\circ} \mathrm{C}$ \\
9. & Pan speed & $26 \mathrm{rpm}$ \\
10. & Spray gun type & Cone type \\
\hline
\end{tabular}

\subsubsection{Drug loading efficiency (\%)}

Accurately weighed quantities of $100 \mathrm{mg}$ stevioside loaded pellets were crushed in a mortar using a pestle and dissolved in $100 \mathrm{ml}$ of $0.1 \mathrm{M} \mathrm{HCl}(\mathrm{pH} \mathrm{1.2)}$. The solution was sonicated for $15 \mathrm{~min}$ and undissolved particles were removed by filtration through membrane filter $(0.45 \mu \mathrm{m})$. The stevioside content in the filtrate was determined by measuring the absorbance at $\lambda_{\max } 331 \mathrm{~nm}$ using UV spectrophotometer (Shimadzu UV-1800, Japan).

The drug loading efficiency (\%) was calculated according to the following relationship;

$$
\text { Drug loading efficiency }(\% \mathrm{w} / \mathrm{w})=\frac{\text { Actual amount of stevioside found in pellets }}{\text { Theoretical amount stevioside in pellets }} \times 100
$$

\subsubsection{Flow properties of pellets}

Stevioside loaded pellets were evaluated for flow properties such as angle of repose, Hausner's ratio, bulk density, tapped density and Carr's index. The angle of repose was determined by funnel method ${ }^{20}$. The accurately weighed amount of pellets was taken in a funnel. The height of the funnel (h) was adjusted in such a way that the tip of the funnel just touches the apex of the heap of the pellets. The pellet was allowed to flow through the funnel on to the surface. The diameter of the formed cone of the pellets was measured and angle of repose was calculated using the fallowing formula;

$\operatorname{Tan} \theta=\mathrm{h} / \mathrm{r}$ or $\Theta=\tan \mathrm{h} / \mathrm{r}$

Where, $\theta=$ angle of repose,

$\mathrm{h}=$ height of pile,

$\mathrm{r}=$ radius of pile base

Bulk density and tapped density was determined by cylinder method ${ }^{21}$. The pellet free of any agglomerates was introduced into a $10 \mathrm{~mL}$ measuring cylinder. After the initial volume was noted, the cylinder was allowed to fall under its own weight onto a hard surface from the height of $2.5 \mathrm{~cm}$ at $2 \mathrm{sec}$ intervals the tapping was continued until no further change in the volume was noted. The bulk volume and tapped volume was noted and density was calculated.

\subsubsection{Friability of pellets}

Friability of pellets was determined using Roche friabilator testing apparatus. Previously weighed pellets were put into the friabilator. The friabilator was revolved at a speed of $25 \mathrm{rpm}$ for $4 \mathrm{~min}$. After the revolution the fines and broken pellets were separated and intact pellets were weighed. The percentage friability was calculated as total weight loss of pellets during the revolution.

\subsubsection{In vitro dissolution studies}

The In vitro drug dissolution study was performed on stevioside loaded pellets filled in capsule using USP dissolution test apparatus II (Electrolab TD7-08L, Mumbai, India). The capsule containing loaded pellets equivalents to $15 \mathrm{mg}$ of stevioside was placed in $900 \mathrm{~mL}$ of $0.1 \mathrm{M} \mathrm{HCl}(\mathrm{pH} 1.2)$ dissolution medium maintained at $37 \pm 0.5^{\circ} \mathrm{C}$ and $50 \mathrm{rpm}$ of paddle speed. At definite time intervals, $5 \mathrm{~mL}$ aliquots were withdrawn, filtered, suitably diluted and analyzed for drug release for $60 \mathrm{~min}$ at $331 \mathrm{~nm}$ using UV-spectrophotometer (Shimadzu UV1800, Japan).

\subsubsection{Fourier transmission infrared (FTIR) spectroscopy}

FTIR spectrum of pure stevioside powder, nonperial pellets and stevioside loaded pellets were recorded by potassium bromide dispersion techniques. About 2-3 mg of each sample were mixed well to form a fine powder with $\mathrm{KBr}$ and analyzed using FTIR spectrophotometer (IRAffinity-1, Kyoto, Japan) in the scanning wavelength region between 4000 and $600 \mathrm{~cm}^{-1}$. The spectrums recorded were carefully examined for any interaction between drug and excipients. 


\subsubsection{Stability studies}

The optimum formulation was subjected stability testing as per the International Conference on Harmonization (ICH) guidelines ${ }^{22}$. The stevioside loaded pellets were filled manually in hard gelatin capsule. The capsules were sealed in aluminum packaging and kept in a polyethylene bottle. The packed container was subjected to accelerated stability testing at $40 \pm 2^{\circ} \mathrm{C}$ and $75 \pm 5 \%$ RH in the humidity chamber (Bio-Technics, India, Ltd.). After the specific time intervals (0, 45 and 90 days) the capsules were withdrawn and observed visually for change in appearance, and drug release (\%).

\subsection{In vivo anti-diabetic study}

\subsubsection{Experimental subjects}

All experiments and protocols performed in the study were approved by the Institutional Animal Ethical committee (Reg. No. KNCOP/ R\&D/ AN-PROT/201213/02), Kamla Nehru College of Pharmacy, Butibori, Nagpur, India. The healthy Swiss albino rats of either sex weighing 150-200 g were employed for the study and were procured form Shree Farm House, Bhandara, India. The animals were housed under standard conditions of temperature $\left(25 \pm 2^{\circ} \mathrm{C}\right)$ and $(12: 12 \mathrm{hr}$ light/dark cycle) with free access to water.

\subsubsection{Study protocol}

The Swiss albino rats were divided into five groups each containing six rats $(n=6)$ and were placed in separate metabolic cages. The blood glucose levels of each animal were determined in fasting state with free access to water. Group I (control group), the animals received normal saline solution through the oral route. Group II (diabetic untreated control), diabetes was induced in animals by giving alloxan monohydrate intraperitonially. Group III (standard control), the animals received the standard drug. Group IV and Group V were treated with the optimized formulation of stevioside pellets containing $15 \mathrm{mg}$ and $30 \mathrm{mg}$ of stevioside respectively and given orally in the form of suspension (prepared with $0.5 \% \mathrm{CMC}$ ) by gastric gavage. Diabetes was induced in animals by the intraperitoneal injection of alloxan monohydrate at a dose $150 \mathrm{mg} / \mathrm{kg}$ body weight. After $48 \mathrm{hr}$ of injection, blood glucose level was measured every day up to seven days. On the seventh day, the animals with blood glucose levels above 250 $\mathrm{mg} / \mathrm{dL}$ were considered as diabetic and used for the study. Group III animals were treated with standard glibenclamide at a dose of $10 \mathrm{mg} / \mathrm{kg}$ body weight and served as reference. The standard drug and test formulation were given daily for a period of 21 days. The blood samples were withdrawn at $0 \mathrm{hr}, 1 \mathrm{hr}, 2 \mathrm{hr}, 3 \mathrm{hr}$, $4 \mathrm{hr}$ and $24 \mathrm{hr}$, after treatment by tail tipping method. Blood samples were analyzed for the blood glucose levels, using glucometer (Glucometer One Touch, Horizon, Life Scan, Johnson and Johnson Ltd.). A drop of blood obtained by tipping tail was placed on customized test strips inserted on glucometer and blood glucose level was read from the digital display ${ }^{23}$.

\subsubsection{Statistical analysis}

Data represented with mean and standard deviation subjected to statistical analysis using one- way analysis of variance. The statistical probability $(p)$ value less than 0.05 was considered to be significant.

\section{RESULTS AND DISCUSSION}

The stevioside loaded pellets were found to be whitish spherical shape, uniform in size and had the smooth appearance. The process parameters for coating were critically monitored and adjusted for optimum performance.

\subsection{Percentage yield and Drug loading efficiency (\%)}

The physical evaluation of stevioside loaded pellets showed good practical yield (75-92\%), excellent drug loading efficiency (69-86\%) (Table 3 ). The yield of loaded pellets prepared with solvent evaporation method was found to be low as compared to suspension layering method. The low yield of pellets with solvent evaporation method might be due to the dissolution or leaching of the drug in a solvent that remains stick to the wall of the container after evaporation of the solvent. The good loading efficiency was noted in loaded pellets prepared with suspension layering method. Therefore, suspension layering method can be exploited as the better method for loading of stevioside on pellets. The results indicated that with the increase in drug concentration in the appropriate solvent the loading efficiency also increases.

Table 3: The evaluation parameters of stevioside loaded pellets

\begin{tabular}{|c|c|c|c|}
\hline Batch code & Yields of Pellets $(\boldsymbol{\%})$ & $\begin{array}{c}\text { Drug loading efficiency } \\
(\boldsymbol{\%})\end{array}$ & Friability (\%) \\
\hline STE1 & $75.24 \pm 2.34$ & $69.92 \pm 3.49$ & $0.76 \pm 0.12$ \\
\hline STE2 & $76.36 \pm 1.87$ & $77.33 \pm 1.15$ & $0.66 \pm 0.13$ \\
\hline STE3 & $78.32 \pm 2.36$ & $78.47 \pm 0.78$ & $0.57 \pm 0.08$ \\
\hline STE4 & $79.23 \pm 1.98$ & $79.61 \pm 1.26$ & $0.76 \pm 0.16$ \\
\hline STL1 & $84.65 \pm 1.54$ & $80.35 \pm 1.18$ & $0.84 \pm 0.11$ \\
\hline STL2 & $86.32 \pm 0.97$ & $81.68 \pm 1.42$ & $0.79 \pm 0.09$ \\
\hline STL4 & $89.56 \pm 1.38$ & $83.61 \pm 1.25$ & $0.62 \pm 0.16$ \\
\hline
\end{tabular}

The values are expressed as a mean \pm standard deviation, $n=3$. 
Table 4: Flow properties of stevioside loaded pellets

\begin{tabular}{|c|c|c|c|}
\hline Batch code & Bulk density $\left(\mathbf{g} / \mathbf{c m}^{\mathbf{3}}\right)$ & Tapped density $\left(\mathbf{g} / \mathbf{c m}^{\mathbf{3}}\right)$ & Angle of repose $(\boldsymbol{\theta})$ \\
\hline STE1 & 0.516 & 0.598 & 26.5 \\
\hline STE2 & 0.513 & 0.587 & 26.9 \\
\hline STE3 & 0.518 & 0.585 & 26.2 \\
\hline STE4 & 0.522 & 0.591 & 26.3 \\
\hline STL1 & 0.519 & 0.611 & 25.6 \\
\hline STL2 & 0.526 & 0.604 & 25.9 \\
\hline STL3 & 0.541 & 0.608 & 25.8 \\
\hline
\end{tabular}

\subsection{Flow Properties}

All the batches showed good flow properties (Table 4) which are desired for proper filling of pellets into a capsule.

\subsection{Friability of pellets}

The friability was found to be less than $1 \%$ for all the batches of stevioside loaded pellets (Table 3 ) suggesting the formulation having required strength and resistibility.

\subsection{In vitro dissolution studies}

The in-vitro drug release studies were performed for all the batches of stevioside loaded pellets in $0.1 \mathrm{M} \mathrm{HCl}(\mathrm{pH}$
1.2). The dissolution profile of all the formulation batches is presented in Fig 1. The formulations STE1STE4 shows drug release $82.18-88.12 \%$, whereas the formulation STL1-STL4 indicate the drug release 92.81$98.31 \%$ at the end of $60 \mathrm{~min}$. The higher percentages of drug release were obtained with the pellets loaded with drug by suspension layering method. Among all the formulations, batch STL4 shows higher drug release $(98.31 \%)$. The in-vitro dissolution data were dealt statistically with one-way ANOVA and the results show the difference in drug release rate are statistically significant.

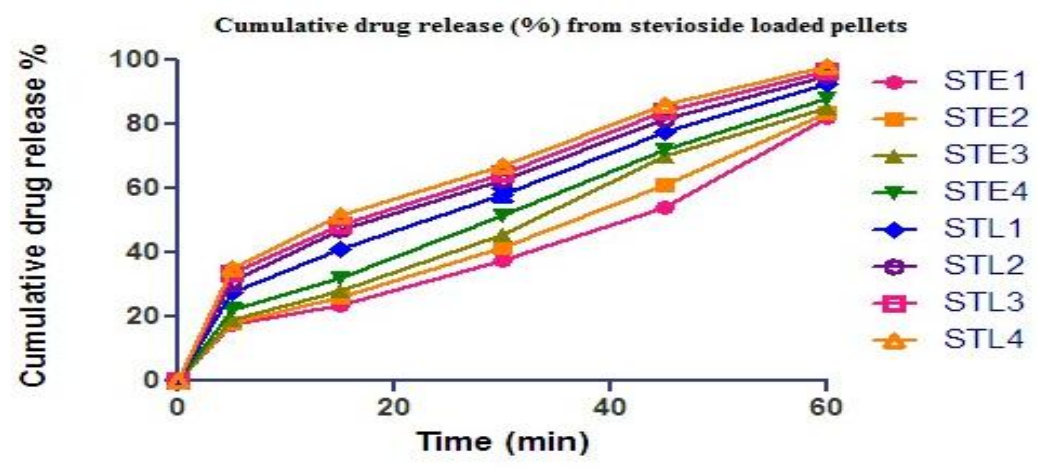

Figure 1: Cumulative drug release $(\%)$ from stevioside loaded pellets. $(\mathrm{SD} \pm \mathrm{Mean}, \mathrm{n}=3$ )

\subsection{Fourier transmission infrared (FTIR)} spectroscopy

FTIR spectrum of pure stevioside and stevioside loaded pellets were presented in Figures 2 and 3. FTIR spectrums of stevioside indicate the presence of major functional groups in the structure which supports its identity. The principle peaks of stevioside observed were $2751(\mathrm{C}-\mathrm{H}), 2812(\mathrm{C}=\mathrm{C}-\mathrm{H}), 1384(\mathrm{O}-\mathrm{H}), 1655.48$ $(>\mathrm{C}=\mathrm{O})$ and 1957 (lactone ring). All the functional peaks were found to be retained in stevioside loaded pellets suggesting no any interaction of drug-excipients.

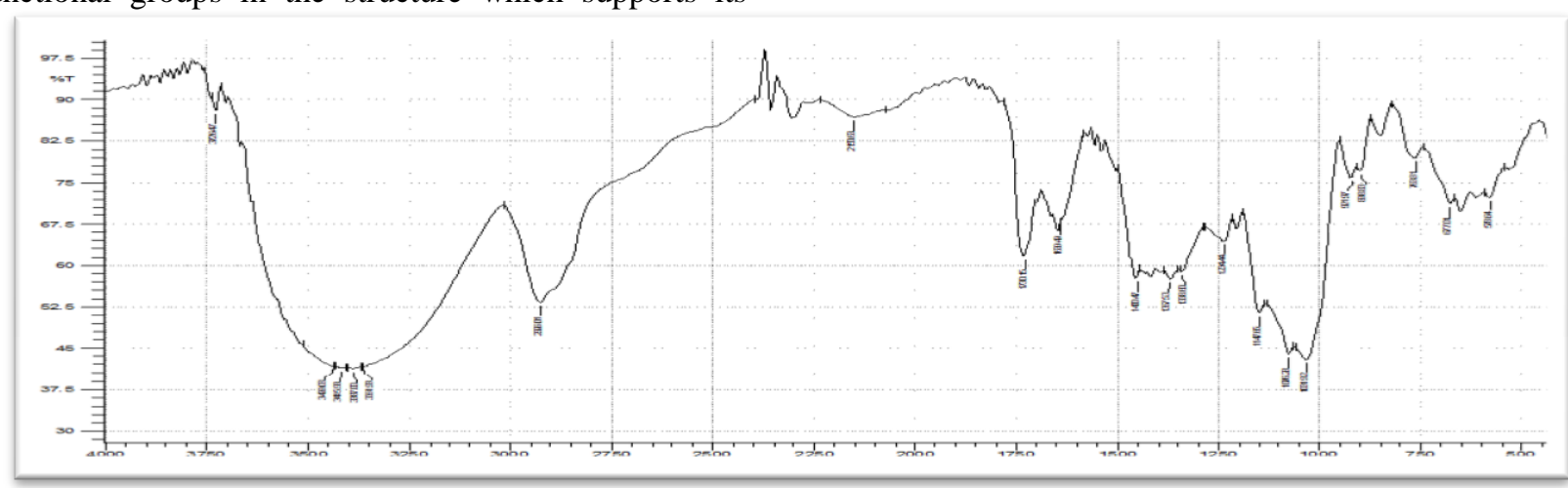

Figure 2: Fourier transform-Infrared spectrum of stevioside powder 


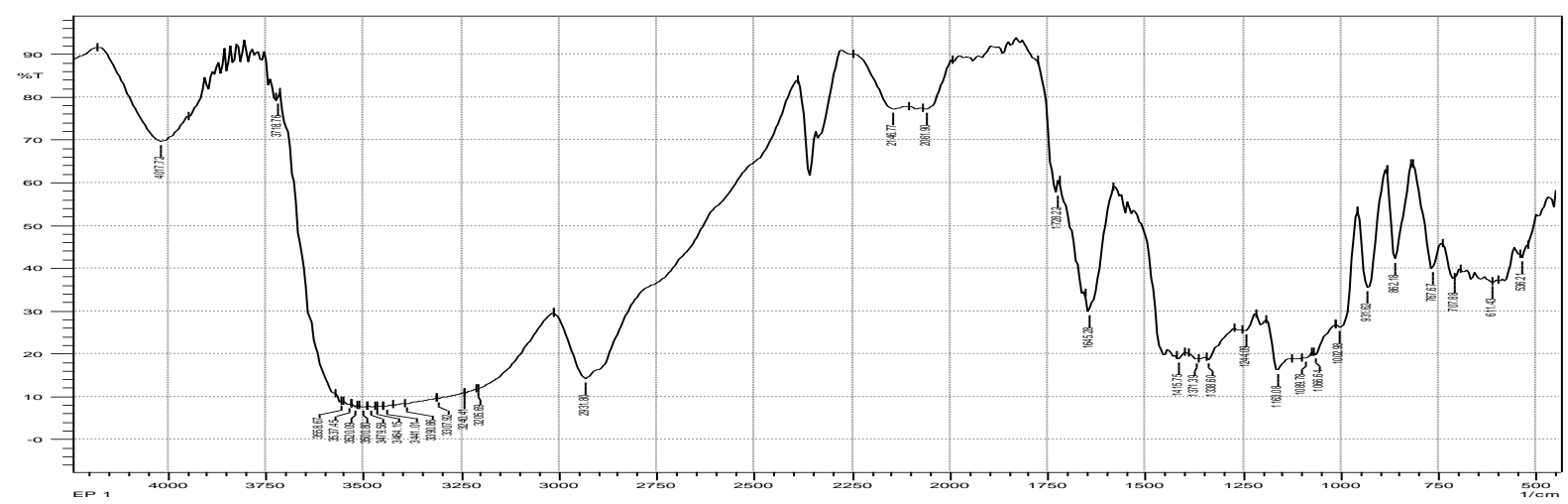

Figure 3: Fourier transform- Infrared spectrum of stevioside loaded pellets

\subsection{Stability studies}

The stability testing was performed on selected formulation SLT 4. The results indicate that there were no notable changes in physical appearance and drug release after subjecting the formulation at $40^{\circ} \mathrm{C} \pm 2{ }^{\circ} \mathrm{C} \&$ $75 \% \pm 5 \% \mathrm{RH}$ for 90 days (Table 4). Therefore, the formulation was found to be stable and retain its stability for 90 days.

Form the observations, the batch STL 4 showed yields $(92.36 \%)$, drug loading efficiency $(86.60 \%)$, friability $(0.74 \%)$, drug release $(98.31 \%)$ within $60 \mathrm{~min}$ and good flow properties and therefore selected as the optimum formulation for carrying in-vivo antidiabetic study.

Table 5: Stability testing data of optimized formulation STL 4

\begin{tabular}{|c|c|c|}
\hline Days & Physical appearance & Cumulative drug release (\%) \\
\hline & Before storage \\
\hline $\mathbf{0}$ & White texture, smooth appearance & $98.31 \pm 0.43$ \\
\hline \multicolumn{3}{|c|}{ After storage } \\
\hline $\mathbf{4 5}$ & No changes observed & $97.43 \pm 0.64$ \\
\hline $\mathbf{9 0}$ & No changes observed & $97.03 \pm 0.98$ \\
\hline
\end{tabular}

*All values are expressed as mean $\pm \mathrm{SD}, \mathrm{n}=3$.

\subsection{In vivo anti-diabetic study}

The results of the in-vivo antidiabetic study in diabetesinduced rats showed a significant decrease in blood glucose levels after oral administration of optimized formulations of stevioside. In order to determine the acute effects on blood glucose levels, the stevioside loaded pellets in two dose levels were administered orally. The variation in the blood glucose levels of individual rats was determined at $0 \mathrm{~h}, 1 \mathrm{~h}, 2 \mathrm{~h}, 3 \mathrm{~h}, 4 \mathrm{~h}$ and after $24 \mathrm{~h}$. Consequently, the significant reduction in blood glucose level was noted in diabetic rats treated with the SLT4 (15mg) and SLT4 (30mg) formulations (Table 6).

Table 6: Acute hypoglycemic effect of stevioside loaded pellets on alloxan induced diabetic rats

\begin{tabular}{|l|c|c|c|c|c|c|}
\hline \multirow{2}{*}{ Groups } & & \multicolumn{2}{|c|}{ Time (h) } & & \\
\cline { 2 - 7 } & $\mathbf{0 h}$ & $\mathbf{1 h}$ & $\mathbf{2 h}$ & $\mathbf{3 h}$ & $\mathbf{4 h}$ & $\mathbf{2 4 h}$ \\
\hline Control & $84.21 \pm 1.53$ & $91.45 \pm 2.34$ & $95.84 \pm 1.95$ & $88.23 \pm 1.17$ & $86.41 \pm 1.05$ & $80.26 \pm 2.31$ \\
\hline Standard & $340.23 \pm 2.97 *$ & $272.42 \pm 3.59 * *$ & $205.64 \pm 4.12 * * *$ & $154.29 \pm 2.14 *$ & $121.33 \pm 3.47 *$ & $119.25 \pm 1.82 * *$ \\
\hline $\begin{array}{l}\text { SLT 4 } \\
15 \mathrm{mg}\end{array}$ & $338.24 \pm 4.52 *$ & $335.46 \pm 4.28 * *$ & $329.87 \pm 3.54 *$ & $342.54 \pm 5.24 *$ & $337.45 \pm 4.21^{* *}$ & $310.25 \pm 5.46 *$ \\
\hline $\begin{array}{l}\text { SLT 4 } \\
\text { 30mg }\end{array}$ & $341.28 \pm 3.87 *$ & $333.78 \pm 3.44 * *$ & $327.46 \pm 4.68 * * *$ & $349.65 \pm 3.20^{* * *}$ & $330.25 \pm 2.98 * *$ & $287.24 \pm 5.18^{* *}$ \\
\hline
\end{tabular}

Each value represents mean $\pm \mathrm{SEM}, \mathrm{n}=6, * p<0.05$ denote value significantly different from control, $* * p<0.01, * * * p<0.001$ denote value significantly different from diabetic control. SEM: Standard error of the mean, $p$ : Probability value. 
Table 7: Sub-acute hypoglycemic effect of stevioside loaded pellets on alloxan induced diabetic rats

\begin{tabular}{|l|c|c|c|c|}
\hline \multirow{2}{*}{ Groups } & & Days & & \\
\cline { 2 - 5 } & 1-day & 7day & 14day & 21day \\
\hline Control & $91.23 \pm 4.71$ & $87.66 \pm 5.12$ & $84.34 \pm 3.28$ & $89.48 \pm 2.8$ \\
\hline Diabetic control & $341.74 \pm 4.42^{*}$ & $355.64 \pm 6.47 *$ & $369.15 \pm 8.67 *$ & $388.57 \pm 9.71 *$ \\
\hline Standard & $340.27 \pm 8.28^{*}$ & $244.25 \pm 7.34 * *$ & $194.56 \pm 7.26^{* * *}$ & $127.71 \pm 8.64 * * *$ \\
\hline SLT 4 15mg & $335.52 \pm 6.74 *$ & $287.29 \pm 5.21 * *$ & $217.36 \pm 4.63^{* *}$ & $176.34 \pm 5.57 * *$ \\
\hline SLT 4 30mg & $333.38 \pm 5.84 *$ & $268.47 \pm 4.87 * * *$ & $204.59 \pm 6.14 * * *$ & $158.73 \pm 4.45 * * *$ \\
\hline
\end{tabular}

Each value represents mean $\pm \mathrm{SEM}, \mathrm{n}=6,{ }^{*} p<0.05$ denote value significantly different from control, ${ }^{* *} p<0.01, * * * p<0.001$ denote value significantly different from diabetic control. SEM: Standard error of the mean, $p$ : Probability value.

\section{CONCLUSION}

The pellets were loaded successfully with stevioside using solvent evaporation and suspension layering methods. The loaded pellets were evaluated critically for various parameters. The in-vivo antidiabetic study in alloxan induced rats shows the significant reduction in blood glucose level after administration of selected formulation. Therefore, the developed pellets can be exploited as a potential antidiabetic formulation to the diabetic patient. The stevioside being sweet in nature could satisfy the desire of sweet in diabetic patients along with its promising anti-hyperglycemic effect.

\section{REFERENCES}

1. Horenstein RB, Shuldiner AR. Genetics of diabetes. Rev Endocr Metab Disord 2004; 5: 25-36.

2. Wild S, Roglic A, Green R, King H. Global prevalence of diabetes estimates for the year 2000 and projections for 2030. Diabetes Care 2004; 27: 1047-1053.

3. King H, Aubert RE, Herman WH. Global burden of diabetes, 1995-2025: prevalence, numerical estimates, and projections. Diabetes Care 1998; 21: 1414-1431.

4. Mohan V, Sandeep S, Deepa R, Shah B, Varghese C. Epidemiology of type 2 diabetes: Indian scenario. Indian $\mathrm{J}$ Med Res 2007; 125: 217-230.

5. Barwal I, Sood A, Sharma M, Singh B, Yadav S C. Development of stevioside Pluronic-F-68 copolymer based PLA- nanoparticles as an antidiabetic nanomedicine. Colloids and surface B: Biointerface 2013; 101:510-516.

6. Bailey CJ, Day C. Traditional plant medicines as treatments for diabetes. Diabetes Care 1989; 12:553-564.

7. Madan S, Ahmad S, Singh G N, Kohli K, Kumar Y, Singh R, Garg M. Stevia rebaudiana (Bert.) Bertoni- A review. Indian J Nat Prod Resou 2010; 1(3): 267-286.

8. Mondaca RL, Galvez AV, Bravo LZ, Hen KA. Stevia rebaudiana Bertoni, source of a high-potency natural sweetener: A comprehensive review on the biochemical, nutritional and functional aspects. Food Chemistry 2012; 132:1121-1132.

9. Prakash I, DuBois GE, Cols JF, Wilkens KL, Fosdick LE. Development of rebiana, a natural, non-caloric sweetener. Food Chem Toxicol 2008; 46(7):S75-82.

10. Goyal SK, Samsher, Goyal RK. Stevia (stevia rebaudiana) a bio-sweetener: a review. Int J Food Sci Nutr. 2010; 61(1): 110 .

11. Melis MS. Effects of chronic administration of Stevia rebaudiana on fertility in rats. J Ethanopharmacol 1999; 67:157-161.

12. Jeppesen PB, Gregersen S, Rolfsen SE, Jepsen M, Colombo $\mathrm{M}$, Agger A, Xiao J et al. Anti-hyperglycemic and blood pressure- reducing effects of stevioside in the diabetic GotoKakizaki rat. Metabolism 2003; 52:372-378.

\section{ACKNOWLEDGEMENT}

We sincerely thanks to the secretary of the Kamla Nehru College of Pharmacy, Butibori, Nagpur, India, for providing the infrastructural facility for carrying out the research work.

\section{DECLARATION OF INTEREST}

We declare that there is no conflict of interest with the content of this article.
13. Jeppesen PB, Gregersen S, Alstrup KK, Hermansen K Stevioside induces anti-hyperglycemic, insulinotropic and glucagonostatic effects in vivo: studies in the diabetic GotoKakizaki (GK) rats. Phytomedicine 2002; 9:9-14.

14. Kujur RS, Singh V, Ram M, Yadava HN, Singh KK, Kumari S, Roy BK. Anti-diabetic activity and phytochemical screening of crude extract of Stevia rebaudiana in alloxan induced diabetic rats. Pharmacog Res 2010; 2:258-263.

15. Geuns JM. Stevioside. Phytochemistry 2013; 64:913-921.

16. Chatsudthipong V, Muanprasat C. Stevioside and related compounds: Therapeutic benefits beyond sweetness. Pharmcol Ther 2009; 121(1):41-54.

17. Roberts A, Munro I. Stevioside and related compounds: Therapeutic benefits beyond sweetness. Pharmcol Ther 2009; 122(3):e1-e2.

18. Jeppesen PB, Gregersen S, Poulsen CR, Hermansen K. Stevioside acts directly on pancreatic beta cells to secrete insulin: action independent of cyclic adenosine monophophate and adenosine triphosphate- sensitive $\mathrm{K}^{+}$ channel activity. Metabolism 2000; 49:208-214.

19. Laila F, Chandran SS. Multiparticulate formulation approach to colon specific drug delivery: current perspectives. J Pharm Sci 2006; 9(3): 327-338.

20. Aulton ME. Pharmaceutics: The Science of Dosage Form Design. $2^{\text {nd }}$ ed. Churchill-Livingstone, London. 2002. p.205206.

21. Sinko P J. Martin's. Physical Pharmacy and Pharmaceutical Sciences. $5^{\text {th }}$ ed. Lippincott Williams \& Wilkins; Philadelphia. 2007. p. 553-556.

22. Orhan N, Aslan M, Orhan DD, Ergun F, Yesilada E. In-vivo assessment antidiabetic and antioxidant activities of grapevine leaves (vitis vinifera) in diabetic rats. $\mathbf{J}$ Ethanopharmacol. 2006; 108; 280-286.

23. Note for guidance on stability testing. Stability testing of new drug substances and products; available from: URL: http://www.tga.gov. access on 12/12/2016. 